\title{
Diversity in Learning Styles: A Rationale for Using Visual Resources in Education for Sustainable Development (ESD) Learning Situations
}

\author{
Prof Cheryl S le Roux
}

College of Education, Department of Educational Foundations, University of South Africa Irouxcs@unisa.ac.za

\section{Doi:10.5901/mjss.2014.v5n27p1644}

\section{Abstract}

Accommodating diverse learning styles and recognising multimodal literacies in teaching and learning contexts significantly influence the way teaching and learning events are approached, facilitated and mediated. Proponents of the multimodal literacies theory suggest that meaning is communicated through a synchronisation of modes, including written language, visual resources, sound and motion, while proponents of theories of learning style preferences identify various learning styles of which visual learning is one. These ways of thinking support the incorporation and use of visual materials in teaching and learning. In such environments, visual resources can be used to provide information and elicit emotions, but, in education for sustainable development (ESD) learning contexts, they can also be used to move learners to thinking critically about the causes and consequences, and for proposing ways of resolving environmental crises and risks. This paper investigates the potential and role of visual resources in encouraging learning, critical thinking, creativity and cooperative learning in ESD learning environments.

\section{Introduction}

There is a marked ascendancy in the use of images and visuals in present-day society to inform, persuade, influence and enlighten and the situation has been described as an evolution from "typographic" to "graphic" human communication (Burns, 2006). It could be argued that, in a powerfully visual society, images can also be meaningfully used in the field of environmental education (EE) to enhance environmental literacy and, in so doing, contribute to education for sustainable development (ESD).

The purpose of educating towards sustainability is to enhance functional, cognitive and critical skills in relation to the environment (Stables, 1998). In practice this means being able to comprehend, respond to and take action on critical environmental issues at local level and, if possible, even extend this to the global level. To do this, it is necessary to understand how the environment functions, how humans interact with, influence and are influenced by the environment, how environmental problems arise and how they can be avoided or solved (Loubser, Swanepoel \& Chako, 2001). Arguably, ESD can be achieved by realising the goals or objectives of EE (Belgrade Charter, 1975) which, in the context and language of the millennium development goals (which in the African context are inseparable from the goals of ESD [UNESCO, 2009]) are as follows:

- creating a perceptual awareness of both natural and human living environments

- transferring knowledge about how the environment functions, which is affected by human intervention and interaction

- developing enviro-positive attitudes based on the values of social justice and ecological sustainability

- acquiring skills that will contribute to identifying, investigating, addressing and solving environmental issues

- advocating active participation that focuses on collective social responsibility

Achieving these goals is paramount to working towards education that supports sustainable development. Learning about the environment is indisputably an activity that relies on observing, analysing and reflecting on the composite reality that surrounds us. A negation of the visual would undeniably be a primary negation of the fundamental nature of what is understood by the concept of environment. 


\section{The Potential for using Visual Resources in ESD}

In EE and ESD learning contexts, the purpose of using visual images would be to contribute towards the accomplishment of the goals of EE listed above. Stated differently, images could be used to

- personalise the concept of environment, raise awareness, develop pro-environmental attitudes and create an understanding of personal responsibility and accountability regarding the environment

- stimulate discussion about to the environment and its issues, and to enrich language use, critical analysis and interpretation skills

- extend knowledge of the environment ranging from local to global contexts (Le Roux, 2008)

Furthermore, Horn (1999) suggests that the incorporation of visual data about the environment in learning contexts has the potential to encourage more holistic ways of considering environmental problems, providing frameworks for intercultural and cross-cultural understanding and contributing to the wider and better understanding of complex environmental issues. Images have a significant ability to draw and focus attention on environmental issues and crises, and the use of images may even force these issues and crises into prominence - more so than written texts could (Hannigan, 2006). Images also have the ability to create a powerful form of environmental storytelling (Robertson, 2007) since they call on viewers to position themselves in relation to the context of the image, to reflect on their interaction with the environment and their obligation towards the environment, and to develop an admiration for the natural world. After all, it is through observations and perception - which is principally visual - that we respond to the world that surrounds us.

\section{Literacy, Visual Literacy and Learning}

Conventional understandings of literacy as reading and writing have been challenged and influenced by technological developments, globalisation and increasing cultural and social diversity (New London Group, 1996). In current academic and colloquial discourse, a multitude of terms such as 'visual literacy', 'digital literacy', 'media literacy', 'cultural literacy', 'techno literacy' and, more recently, 'silicon literacy' and 'hypermodality' are encountered (Walsh, 2003). Such terminology reflects attempts to explain and understand literacy and learning within changed learning contexts and to establish new learning paradigms. Two of the most recent insights into the field of literacy are the ideas of 'multiple literacies' (New London Group, 1996; Street, 1995; Unsworth, 2001) (also referred to as 'multimodal' literacies [Kress, 1997]); or 'new' literacies (Lankshear \& Knobel, 2003)) and 'literacy as social practice' (Street, 1995).

What, then, is visual literacy and how does it fit into contemporary views on literacy? This research in relation to visual literacy takes as point of departure the early work of Debes $(1968,1969)$, Arnheim (1969), Dondis (1973), Moore and Dwyer (1994) and more recently the Delphi Study conducted by Brill, Kim and Branch (2001) who through their research have advanced the legitimacy of visual messaging as a bone fide language. Despite the fact that there appears to be no single definition of visual literacy, the term is generally used in such a way as to encompass the ways people perceive objects, and interpret and learn from what they see (Elkins, 2008). Shifrin (2008) argues that visual literacy uses the same competencies as phonetic literacy: decoding, comprehension and interpretation. Using different terminology, Messaris (1994) outlines the essence of visual literacy as the ability to describe and analyse visual data, pointing out that the focus is on causality, on contingent relationships, on the hypothetical and on estimates of likelihood. McMullen and Woo (2002) hold that visual literacy involves thinking critically and analytically about visual information in order to assess the meaning and intention of that information, and using these skills to create new forms of visual communication. Brill, Kim and Branch (2001) describe visual literacy as

... a group of acquired competencies for interpreting and composing visible messages. A visually literate person is able to: (a) discriminate, and make sense of visible objects as part of a visual acuity, (b) create static and dynamic visible objects effectively in a defined space, (c) comprehend and appreciate the visual testaments of others, and (d) conjure objects in the mind's eye.

A 'literate' person is able to decipher the basic code and syntax, interpret signs and symbols, correctly apply terms, understand how things fit together, and work out and design or create new products. The skills or competencies alluded to point to both cognitive and social-practice or social-constructive approaches to skills or competencies development, which fit well with current thinking in relation to the nature and scope of learning. The deduction of a range of competencies from the operational definitions furthermore serves as a basis for beginning to understand what one needs to know and be able to do to be visually literate. This, in turn, enables educators to establish how visual literacy can be taught and applied in the learning environment. 


\section{Facilitating the Development of Visual Literacy}

Like a printed text, an architectural blueprint, a mathematical equation or a musical score, a visual image has its own language. That people need to be taught to read, and that they learn to read, is an accepted fact. Similarly, visual literacy is an acquired skill which can be developed and enhanced.

To develop visual literacy, fundamental skills of accurate observation, understanding and comprehension of visual relationships are paramount. Dallow (2008) and Shifrin (2008) both argue that, as visual images become more intricate and elaborate, the ability to observe, identify, describe and analyse the features, situations, ideas, feelings and concepts within visual signs needs to be developed. Images need to be deconstructed of overt and covert information. Engaging in these actions constitutes a cognitive operation in which comprehension, analysis and synthesis of the visual commentary is foremost (Burns, 2006).

Burns (2006), Bamford (2003) and Shifrin (2008) argue that developing visual literacy and cultivating the skills needed to interpret the content and context of visual images are gained through training in visual analysis and through repeated engagement with visual materials. Strategies to promote visual literacy, namely developing and enhancing the skills referred to above, would include exposure to images and interacting with those images through thoughtful and thought-provoking questioning and discussion (Bamford, 2003).

Clearly, one needs to move from treating images simply as records of reality to recognising their symbolic and metonymic quality within systems of imagistic representation. Images contain complex cultural and material content, and their interpretation is not simply a question of seeing. They are not mere conduits of meaning, but are locations through which meaning is mediated (Veen 1998). The visually literate individual will thus look at an image carefully, critically and with an eye for the intentions and assumptions of its creator (Thibault \& Walbert, s.a.).

\section{Why Incorporate Visual Material into Tuition Processes?}

Apart from the gains of using visual materials in ESD contexts discussed previously, other arguments supporting the use of visuals in teaching and learning contexts can also be raised. Changes in the social environment and means of communication are making new demands on education, which has, as priority, preparing the youth to participate and contribute meaningfully in current and emerging social contexts. The world of communication has become multimodal and is no longer reliant on language-as-speech or on language-as-writing alone (Kress, 2000). Bleed (2005) argues that visuals created with new technologies are changing what it means to be literate and that in the $21^{\text {st }}$ century the ability to create and interpret visual media or 'text' is a form of literacy as basic as being able to read or write. Visual literacy is as important as textual literacy. From an educational viewpoint, the benefit of developing visual literacy revolves particularly around empowerment, defined as the process through which learners learn to appropriate knowledge outside their immediate experience in order to broaden their understanding of themselves, of the world and of the possibilities of transforming assumptions about the way we live (McLaren, 1989).

The points mentioned below relate to the benefits of incorporating visual resources in the learning environment and the acquisition of incremental levels of visual literacy in educational contexts. This list is not comprehensive, but should serve as a justification for expanding the pedagogical space by including visual materials in learning contexts and developing visual literacy.

\subsection{Visual learning accommodates visual learners' preferred learning style}

Gardner's pioneering work on multiple intelligences in the 1980s identified visual intelligence as one of seven intelligences (cf Gardner, 1983). Anderson (2003) estimates that at least $60 \%$ of learners can be categorised as visual learners and providing opportunities for, and acknowledging visual learning, gives those whose preferred learning style is visual the opportunity to excel and to build a sense of self-worth and competence (cf Farmer, 2007).

Drawing on Gardner's theory ${ }^{1}$ (cf Gardner 1983) which forged the notion of multimodal learning styles, it can be deduced that, for a learner to benefit optimally from learning experiences, the curriculum and instructional design should accommodate individual interests, learning preferences and abilities. According to Gardner, the seven kinds of intelligence allow seven ways to teach rather than one. Furthermore, all seven intelligences are needed to live life well,

${ }^{1}$ Gardner's theory of multimodal learning has subsequently been substantially revised and broadened to include other learning styles, however for the purpose of exploring the realm of visual learning the original theoretical framework served the purpose well. The research instrument (Smith 2008) used in the empirical study tested the seven intelligences that were identified in Gardner's early work. 
and teachers therefore need to attend to all of them and not just linguistic and logical-mathematic which has traditionally been their core concern (Hatch \& Gardner, 1993; Smith, 2008). Consequently, using visual resources in learning situations particularly benefits learners whose cognitive learning style is predominantly visual. In addition, learners who have language barriers or hearing disorders may well benefit from having visual instructional materials incorporated into their learning programmes (Marshark, Pelz, Convertino, Sapere, Arndt \& Seewagen, 2005).

\subsection{Using visual resources in teaching enhances learning in general}

Visual literacy precedes verbal literacy in human development, since visual symbols are non-verbal representations that precede verbal symbols. Visual literacy is the basic literacy in the thought process and is the foundation for reading and writing - we 'saw' before we 'read or wrote'. Developing skills in visual literacy and analysis strengthens the development of verbal literacy as the spoken or written word (Stokes, 2000).

\subsection{Incorporating visual materials facilitates the development of critical-thinking skills}

Engagement with visual materials stimulates the development of visual literacy skills, and stimulates discussion, critical verbal engagement, negotiation and interaction with others (Le Roux, 2009) because, to understand visual messages, more is needed than mere perceptual and everyday cognitive skills. Higher-order thinking skills are essential for making sense of, analysing, interrogating, synthesising and evaluating images.

Ewen (1988) comments that we are educated from infancy to look, but are not encouraged to see and interpret simultaneously. Our eyes take in images with little critical resistance, but indeed, images are not necessarily direct mechanical records of the world around us and can be framed, focused and decontextualised. Images need to be examined attentively and interpreting them requires refined critical-thinking skills, that is, analysis, explanation, evaluation, interpretation, reflection and using reason and evidence to make judgement calls.

\subsection{Including visual resources in learning environments establishes opportunities for cooperative learning}

Education has as its purpose to prepare children for a life of lifelong learning and to develop abilities and competencies required in the $21^{\text {st }}$ century. A holistic approach to learning that would meet these expectations is advanced through cooperative and integrated learning and teaching opportunities. When visual materials are introduced into a teaching and learning environment such as this, interest in and attention to the work are encouraged and critical enquiry is promoted (Shifrin, 2008). Engaging with visual resources requires reflective engagement with the resources and with peers, since, as Crouch (2008) points out, engaging in activities around visual resources is not a solitary, individual action but part of a wider set of social practices which require and encourage interaction, dialogue, negotiation and critical mutual engagement in conscious thought.

Because pictures provide a high level of interest and may be seen as less threatening than text, they invite commentary and discussion. Inventive thinking and effective communication are logical gains associated with cooperatively engaging with visual data in a learning situation.

These thoughts on the potential of visual materials to promote meaningful learning underpinned the rationale for and design of the research undertaken to determine the potential for using visual resources in ESD learning contexts.

\section{Research Problem Statement}

ESD involves teaching about environmental issues - about raising awareness, increasing knowledge, establishing proenvironmental attitudes, helping individuals make informed decisions and becoming involved and taking action that addresses or prevents the occurrence of environmental issues. The context within which an environmental educationist works is predominantly a practical, real-life situation. On the other hand, teaching in an ODL context - such as that within which the reported research occurred - tends to gravitate to the written word with study guides, tutorial letters and textbooks occupying a central position. The researcher's underlying assumption was that, given the nature of ESD, if students were afforded greater opportunity to engage with visual materials in their learning, they would find learning about the environment more meaningful and relevant and this would in turn improve the quality and value of their learning. 


\section{Research Context}

For the past 10 or more years, each year, lecturers involved in teaching EE in the institution where the research was conducted, have presented a four-day EE workshop for students enrolled in EE programmes at the institution. Workshop participants are students registered for the BA and BSc Environmental Management programmes, the Advanced Certificate in Environmental Education, students enrolled in the Honours BEd programme specialising in EE and a certificate programme for Environmental Educators. Workshop attendance is voluntary, except for the Certificate Course students for whom the workshop is an integral part of the practical module that forms part of the qualification. Those who attend voluntarily have the option of choosing to have the workshop assessment mark that is awarded at the culmination of the workshop count as an assignment mark. If they choose this option, they do not have to submit their third or final assignment for the particular EE module for which they are registered.

On the first day of the workshop, workshop participants are introduced to the underlying philosophy and principles of the workshop and it is explained that their active participation is essential for the workshop to succeed and for them to benefit most. They are informed that their involvement and participation will be observed and will contribute towards the assessment mark. Participants are encouraged to voice their opinions, raise questions, debate and discuss topics and share their own experiences during the workshop. It is explained that presenters will also be engaged in facilitating their learning by supporting, observing and commenting on interactions. Summative assessment occurs on the last day of the workshop when participants present an EE programme that they have designed for a group of learners of their choice. The presentation should incorporate elements that were dealt with during the workshop presentations, for example the nature of the programme and its delivery should meet the goals of EE while taking into account the age, context and needs of the individuals for whom the programme has been developed.

During the workshop presentations on the first three days both theoretical and practical components related to teaching about the environment are covered. The theoretical component which is presented by the researcher on the second day of the workshop explores issues that are pertinent to teaching practice and specifically to teaching EE and ESD. The topics covered on the second day include learning styles and learning preferences, teaching different age groups, teaching strategies and programme development and presentation. Each of these themes is explored in a cooperative learning environment with group work and discussion being central to the learning experience. Workshop participants are also given the opportunity to determine inter alia their own learning styles and preferences and to test the outcomes of the exercise against their personal experiences - an issue which is pertinent to the research reported in this paper.

\subsection{Research sample}

The research was undertaken at the EE workshops held in August for four consecutive years. EE students were notified of the workshops through tutorial letters and announcements placed on the e-learning discussion forum site and were invited to attend. Certificate Course students are obliged to attend the workshop since it is an integral part of the learning programme. All workshop participants participated in the research and thus constituted the research sample. Workshop attendance over the four years is summarised in Table 1 below.

Table 1: Workshop attendance per year

\begin{tabular}{|l|c|c|c|}
\hline Year & Voluntary attendance & Compulsory attendance & Total \\
\hline First year & 29 & 18 & 47 \\
\hline Second year & 6 & 11 & 17 \\
\hline Third year & 1 & 16 & 17 \\
\hline Fourth year & 2 & 12 & 14 \\
\hline
\end{tabular}

The significant decrease in voluntary attendance experienced after the first year is attributed to a decision taken by the institution to discontinue all programmes with fewer than 300 registered students.

\subsection{Research design}

In order to test the underlying research assumption articulated previously that EE students' learning would benefit from tuition that is supported by the use of and which includes opportunity for engagement with visual materials, a mixed 
method research design was followed.

The study commenced with a theoretical study that explored the concept of multimodal learning and visual intelligence. Next, the phenomenon of visual literacy was studied and this was followed by a study of strategies employed to analyse visual data such as photographs and illustrations. The purpose of this aspect of the research was to establish means of developing and enhancing visual literacy. These theoretical studies informed the quantitative and qualitative research component of the research which involved the following processes:

1. Determining the effectiveness of visual data analysis tools in enhancing visual literacy

2. Establishing workshop participants' learning style preference

3. Assessing workshop participants' responses to analysing visual material when using a variety of visual data analysis approaches

4. Evaluating workshop participants' responses to engaging with similar EE activities presented in written form and in visual form

\subsubsection{Assessing the effectiveness of visual data analysis tools}

Students who attended the first workshop were randomly grouped into six groups of either seven or eight members. The researcher provided a brief introduction regarding the use of visual materials in teaching about EE issues. It was explained that the following activity involved engagement with visual material which would, on completion, serve as the basis for further discussion and debate. Each of the six groups was then provided with an A4 colour photograph of an environmental issue which they were asked to study in depth. They were asked to identify the environmental issue portrayed and to try to establish as much information from the photograph as possible. Two groups were provided with a visual data analysis worksheet $A$ to aid them in the task, while another two groups were provided with a visual data compositional analysis worksheet $B$, which was to be used to guide their study of the photograph. The remaining two groups were not provided with any visual data analysis tools to aid them in the analysis of the photograph.

\subsubsection{The visual data analysis guides and worksheets}

Worksheet A was based on a visual data analysis tool designed by the education staff at the United States National Archives and Records Administration (s.a.). The worksheet is designed to specifically focus users' observations. After a two-minute careful study of the photograph or illustration, users are asked to divide the picture into quadrants and again study each quadrant in detail. The purpose of this is to focus observation at an even more specific level. Users are then asked to identify and list people, objects and activities observed. Further guidance in relation to the analysis of the illustration is provided through questions that necessitate deduction and reflection.

Worksheet B comprises a worksheet of 12 questions aimed to guide users in interpreting an illustration or photograph in terms of composition and content. The worksheet was developed using the theoretical and conceptual framework purported by Rose (2001) in relation to visual data analysis. Users are guided to focus their observations on foreground and background elements, as well as to reflect on the creation of the picture in terms of intended purpose, use and inferences that can be made.

During the half hour allowed to study the photograph, the researcher moved among the groups observing their interactions and discussions and, specifically, their use of the data analysis worksheets. The researcher refrained from engaging with the groups in their discussions or assisting with the analysis of the photograph.

When the time was up, groups were asked to report on their experiences and to elaborate on the value and effectiveness of the data analysis instrument that was used in the group.

\subsubsection{Establishing workshop participants' learning style preferences}

All workshop participants completed the Multiple Intelligence Test developed by Smith (2008) based on Howard Gardner's Multiple Intelligences Questionnaire. This test comprises 28 items and is self-scored. After the test was scored, students then transferred the numerical scores from each intelligence category of the test and plotted them on the Multiple Intelligence Wheel. The resulting diagram was then shaded to provide a visual representation of each student's intelligence preference. Students were asked to report their learning style preference which was subsequently recorded by the researcher. 


\subsubsection{Evaluating workshop participants' responses to engaging with like EE activities presented in written and visual form}

As an orientation to the workshop programme for Day 2 in workshops 2, 3 and 4, students were asked to run through the previous day's learning experiences and recap key environmental concepts and definitions. Students (who were grouped into three groups of five or six members each) were then directed to an activity in their manual which lists various critical environmental issues experienced locally and globally. From the list of seventeen issues, the groups were asked to select three issues and discuss each one within the group, paying particular attention to causes, consequences and methods of addressing the issues. Students were asked to record their answers in their manual. A time limit of 20 minutes was place on this activity. During this time, the researcher moved among the groups following discussions and providing support where necessary - for example to clarify terminology and concepts for example the differences between cause and effect, contributing factors and consequences. Field notes were made by the researcher of the various groups' interactions and the level of interest shown, depth of discussion and engagement and degree of participation in the activity. Groups were not required to provide a general report back to the whole group after completion of the activity.

During the afternoon session, each group in each of the three workshops was provided with an A4 photograph portraying an environmental issue. The groups were asked to study the photograph and identify the environmental issue. They were also asked to consider what factors could have contributed to the development of the issue, and to discuss the consequences of the issue. Students were also asked to suggest ways in which the problem could be addressed and possibly resolved. A time limit of 20 minutes was placed on the activity. During these 20 minutes, the researcher moved between the groups and observed and took note of group members' responses, level and depth of interest and engagement with the activity at hand.

\section{Research Results - Findings and Discussion}

\subsection{Visual data analysis worksheets}

In the first workshop, the students who attended the workshop were divided into six groups each comprising seven or eight members. Two visual data analysis worksheets were tested by four groups during this workshop. The remaining two groups were given the same activity as these four groups, but were not provided with data analysis worksheets or any form of additional visual data analysis assistance - apart from the verbal instruction to carefully study and report on the illustration provided.

\subsubsection{Worksheet $A$}

Both groups that used data analysis worksheet A made good progress at first. When the illustration had to be divided into quadrants, it so happened that the key figures in the illustration were bisected and this 'confused' the users who were expected to focus on each quadrant independently. A great deal of discussion within both groups took place regarding how this perceived problem should be dealt with. Members of one of the group decided that the purpose of that particular aspect of the activity was to identify lesser elements in the illustration that had been previously 'hidden' and moved on to study each quadrant in greater depth. For the other group, the fact that the main characters in the illustration had been bisected remained an ongoing point of discussion. Once both groups moved on to the next part of the worksheet that called for deductions and reflection on questions raised by the illustration, the discussion within the groups and engagement with the illustration became animated and interactive. Members of the group spontaneously shared their own experiences and opinions and this in turn led to lively discussion and debate. Both groups remained actively engaged in their task throughout the 30 minutes allocated to the activity.

\subsubsection{Worksheet $B$}

Both groups struggled with the terminology used in the worksheet - especially the terms used in the headings, namely compositional and contextual analysis. These terms were clearly unfamiliar within the context of the activity. Both groups also struggled with the probing questions and had difficulty in understanding what was expected of them. Their responses - which they wrote down in the space provided - were rather stilted and tentative. One group specifically struggled with explaining the relationship between foreground and background elements and much time was spent in trying to find the 'correct' answer. Although both groups remained actively involved in the activity and discussion, and debate was ongoing, 
the researcher sensed that the groups were perhaps intimidated by the questions and the fact that they were struggling to understand and find the required responses. Answers were tentative and there were very few instances where the responses were emphatic or clear. When time was called, some members in one of the groups were clearly relieved that they no longer had to continue with the exercise!

\subsubsection{Verbal instruction}

In the groups where no visual data analysis worksheet had been provided, students followed the verbal instruction of identifying and analysing the environmental issue illustrated in the photograph. In both groups, participants made accurate observations and deductions regarding the issue portrayed. Discussions were animated and several of the group members related their own experiences in relation to the issue portrayed. One group member was full of advice about how the issue should be dealt with and was especially harsh in criticising the way the people portrayed in the photograph were abusing their environment! This led to a heated discussion headed by more 'moderate' or 'tolerant' individuals and this resulted in the quieter members of the group also entering the debate and airing their opinions. Up until the end of the activity students in both groups continued to engage enthusiastically with the activity.

From the observations made during this activity, the researcher was persuaded that, although the groups that had used worksheet $A$ had perhaps probed the illustration in greater depth, the groups that clearly participated most spontaneously in the activity had been those who had not been provided with a worksheet to guide their investigation and who had responded only to verbal instructions. This was an unanticipated finding since the researcher had assumed that the groups would have preferred having some form of guidance in their analysis of the photograph. The users of worksheet B clearly struggled most of all the groups and least enjoyed the activity. However, when the groups were asked to give feedback about how they had experienced using the worksheets, all four groups said that the worksheets had been useful - although the groups using worksheet B commented that it had been a very challenging exercise and that they were uncertain of whether their responses had been what was called for. It appeared that the groups who had not been provided with a worksheet were no worse off for not having had additional support and that they had been able to engage meaningfully with the activity.

The researcher was thus not convinced that the worksheets had made any significant contribution to the quality of engagement in and analysis of the visual material presented at the workshop. Based on this observation (and similar responses to the use of the visual data analysis worksheets obtained when their use was workshopped at an international conference: the Common Ground Conference entitled New Directions in the Humanities in Turkey in 2008) it was consequently decided to defer use of the worksheets in their current format and to consider revising and refining them if the need arose at a later stage.

\subsection{Learning style preferences}

Table 2 below provides a summary portraying, in approximated percentages, participants' dominant learning style preference per group. In the bottom row of the table, the average frequency of participants' learning style preferences of the four workshops is provided.

Table 2: Workshop participants' learning style preferences

\begin{tabular}{|c|c|c|c|c|c|c|c|}
\hline & Linguistic & Mathematical & Visual & Musical & Interpersonal & Intrapersonal & Kinesthetic \\
\hline $\begin{array}{c}\text { Workshop } 1 \\
n=47\end{array}$ & $\begin{array}{c}26 \% \\
12\end{array}$ & $\begin{array}{c}13 \% \\
6\end{array}$ & $\begin{array}{c}26 \% \\
12\end{array}$ & $\begin{array}{c}4 \% \\
2\end{array}$ & $\begin{array}{c}16 \% \\
8\end{array}$ & $\begin{array}{c}11 \% \\
5\end{array}$ & $\begin{array}{c}4 \% \\
2\end{array}$ \\
\hline $\begin{array}{c}\text { Workshop } 2 \\
n=17\end{array}$ & $\begin{array}{c}24 \% \\
4\end{array}$ & $\begin{array}{c}12 \% \\
2\end{array}$ & $\begin{array}{c}29 \% \\
5\end{array}$ & $\begin{array}{c}0 \% \\
0\end{array}$ & $\begin{array}{c}29 \% \\
5\end{array}$ & $\begin{array}{c}6 \% \\
1\end{array}$ & $\begin{array}{c}0 \% \\
0\end{array}$ \\
\hline $\begin{array}{c}\text { Workshop } 3 \\
n=17\end{array}$ & $\begin{array}{c}17 \% \\
3 \\
\end{array}$ & $\begin{array}{c}12 \% \\
2 \\
\end{array}$ & $\begin{array}{c}29 \% \\
5\end{array}$ & $\begin{array}{c}0 \% \\
0\end{array}$ & $\begin{array}{c}24 \% \\
4\end{array}$ & $\begin{array}{c}12 \% \\
2 \\
\end{array}$ & $\begin{array}{c}6 \% \\
1 \\
\end{array}$ \\
\hline $\begin{array}{c}\text { Workshop } 4 \\
n=14\end{array}$ & $\begin{array}{c}29 \% \\
4\end{array}$ & $\begin{array}{c}0 \% \\
0\end{array}$ & $\begin{array}{c}21 \% \\
3\end{array}$ & $\begin{array}{c}0 \% \\
0\end{array}$ & $\begin{array}{c}36 \% \\
5\end{array}$ & $\begin{array}{c}14 \% \\
2\end{array}$ & $\begin{array}{c}0 \% \\
0 \%\end{array}$ \\
\hline Average $\%$ & $24 \%$ & $9 \%$ & $26 \%$ & $1 \%$ & $26 \%$ & $11 \%$ & $3 \%$ \\
\hline
\end{tabular}

When the results of the four workshops workshop participants' preferences for learning styles are compared, it becomes evident that, in all four samples, visual learning was a preferred learning style, although in the first sample, visual and 
verbal learning styles were equally preferred, in the second group visual and intrapersonal learning styles were equally preferred while in the fourth group students indicated a preference for interpersonal (36\%) and verbal learning (29\%). When the data from all four workshops is collated, the results indicate that, overall, students showed a slight preference for visual learning (26\%) and interpersonal (26\%) learning, with linguistic learning styles in second place (24\%).

The results from Anderson's research (2003) also indicated a preference for visual learning. However, his study indicated a much higher incidence of visual learners - $60 \%$ as opposed to $24 \%$ - as was evidenced in this study. In essence, it would be wrong to compare the two studies since no attempt was made to replicate context, sample structure and composition. However, the overall deduction arrived at in both studies is that, generally, visual learning is a significant learning style preference and this fact could be used to justify the inclusion of opportunities for engagement with visual learning resources in teaching and learning contexts.

\subsection{Comparison between activities presented in written and visual form}

This part of the research was carried out with groups attending the second, third and fourth workshops.

In the first activity, students selected three environmental issues from a list of 17 issues presented in the workshop training manual for discussion. The researcher observed the groups during their engagement with this activity. The groups dealt with the task at hand in a distinctly academic and theoretical way. Causes and consequences were mentioned and carefully written down in the manual. Group members noted what the group's scribe had written and carefully copied this into their own manuals. Very little reflective discussion was apparent. Groups focused on filling in their answers in the accompanying table in the manual, and once this was done, they moved to the next issue and approached it in the same way. By the end of the session, groups that had completed the task before the twenty minutes were up were engaged in discussions that had no bearing on the task. All groups successfully completed the task.

In the second activity presented later on the same day, students were given an A4 photograph depicting an environmental issue. They were asked to study the photo, identify the issue and to suggest possible causes, consequences and ways of dealing with the problem. Twenty minutes was allotted to the task. Students who struggled to see the picture, got up and stood behind group members seated at the middle of the desk so that they could get a clearer view of the photograph.

The groups studied the photograph and with little hesitation suggested what issues were portrayed. In all the groups, members argued and debated which issue was dominant since the photograph could indeed be interpreted differently. The picture was of three youths standing on the banks of an obviously polluted river in a squatter area. Students debated whether the core environmental issue was water pollution, land degradation, urbanisation, poverty, inadequate waste disposal or perhaps housing. In each instance, the groups had to reach consensus regarding the core issue since the rest of the activity would be directed by this decision. In one group, where only a measure of consensus regarding the core issue had been reached, those who were still not entirely in agreement continued to try to direct the discussions in the direction of their preferred choice of topic. Despite the lack of agreement, discussions among the group members remained meaningful and contributed to elucidating causes and consequences of what had now become two core issues.

In one of the groups at the third round of workshops, one of the members is employed by a waste management organisation and he shared his experiences with the other members of his group of working in similar circumstances as portrayed in the photograph. He raised several interesting points of discussion and members of his group used the opportunity to ask questions about the nature and challenges of his work. Although he dominated the discussion, the other members of the group were actively involved in questioning him and getting first-hand information about a topic with which they were not equally well versed. His contribution to the discussion proved very useful and enlightening and clearly raised his worth as a group member! During the afternoon break the researcher observed how two of the group continued the discussion with the waste management specialist!

The researcher observed how several students related personal experiences of similar conditions and shared ways of how their communities had dealt with the issue. It was interesting to note how group members debated the feasibility of strategies and commented on ways the intervention strategies could be improved or adapted to other contexts. Without exception, all groups remained actively involved in their discussions for the full duration of the time allotted to the activity and the researcher struggled to call the group to order.

When the level of engagement, depth of discussion and extent of active engagement in the two activities - the one written and the other visual - were compared, there was no doubt that students were more animated, engaged in more meaningful debate and were more forthcoming in contributing to the discussion when the activity involved a visual stimulus than when dealing with the written text. There were obvious opportunities for critical thinking, analysis and 
debate in both scenarios, but the visual image had clearly been a stimulus to engage students in debate and dialogue. It seemed as if the photograph had in some way reached out to the group and drawn them into a discussion and reflection.

\section{Conclusions}

This paper has introduced an argument for using visual data in ESD learning contexts. It has also argued the importance of developing visual literacy given that a significant proportion of students' preferred learning style is visual. One of the main arguments and assumptions underlying the research was that the use of visual data analysis instruments would significantly enhance students' ability to interpret and analyse visual resources. The research indicated no significant improvement in the ability of participants to analyse and engage with visual resources when their observations and analysis was guided by visual data analysis tools. The reason for this finding can only be found in speculation at this point in time.

A further underlying assumption that underpinned the research was that students' ESD learning would be enriched by the inclusion of visual materials and that they would find learning about the environment more meaningful and relevant if they were expected to engage actively with visual resources. It was found that the photographs used in the study considerably stimulated engagement and discussion. Since photographs are open-ended and can be interpreted in various ways, this encouraged the exploration of issues, and made the students aware that not everyone perceives the world in the same way and that people respond to issues differently. The photographs used provided a rich opportunity for exploration, discussion and engagement and were more successful in achieving the learning outcomes than text activities had been.

The research reported above suggests strongly that the inclusion of visual materials in students' learning experiences in a cooperative learning environment contributes to personalising learning about environmental issues and risks, stimulates discussion and critical debate and affords students the opportunity to extend their knowledge in support of ESD.

\section{References}

Anderson, D. (2003). A picture is worth $\$ 10$ Million: adult object permanence and the neglected power of sight. Association of Environmental and Resource Economists Newsletter 23(1),1-4.

Arnheim, R. (1969). Visual thinking. Berkeley: University of California Press.

Bamford, A. (2003). The visual literacy white paper. www.adobe.com/uk/education/pdf/adobe_visual_literacy_paper.pdf , visited on 9 August 2008.

Belgrade Charter. (1975). A global framework for environmental education. http://portal.unesco.org/education/en/file_download. php/47f146a292d047189d9b3ea7651a2b98The+Belgrade+Charter.pdf, visited on 8 August 2008.

Bleed, R. 2005. Visual literacy in higher education. http://net.educause.edu/irl/ibrary/pdf/ELI4001.pdf , visited on 28 August 2009.

Brill, J.. Kim, D. \& Branch, R. (2007). Visual literacy defined - the results of a Delphi Study: can IVLA (operationally) define visual literacy? Journal of Visual Literacy 27(1), 47-60.

Burns, M. (2006). A thousand words: promoting teachers' visual literacy skills. MultiMedia and Internet@Schools 13(1),16-20.

Crouch, C. (2008). Afterword, in Visual literacy, edited by J Elkins. New York: Routledge.

Dallow, P. (2008). The visual complex, in Visual literacy, edited by J Elkins. New York: Routledge.

Debes, J.L. (1968). Some foundations of visual literacy. Audiovisual Instruction. 13, 961-964.

Debes, J.L. (1969). The loom of visual literacy: an overview. Audiovisual instruction. 14(8), 25-27.

Dondis, D.A. (1973). A primer of visual literacy. Cambridge: MIT Press.

Elkins, J. (2008). The concept of visual literacy and its limitations, in Visual literacy edited by J Elkins. New York: Routledge.

Ewen, S. (1988). All consuming images: the politics of style in contemporary culture. New York: Basic Books.

Farmer, L.S.J. (2007). I see I do: persuasive messages and visual literacy. MultiMedia \& Internet@Schools 14(4),30-33.

Gardner, H. (1983). Frames of mind: the theory of multiple intelligences. New York: Basic Books.

Hannigan, J.A. (2006). Environmental sociology. New York: Routledge.

Hatch, T. \& Gardner, H. (1993). Finding cognition in the classroom: an expanded view of human intelligence, in Distributed cognitions: psychological and educational considerations, edited by G Salomon. Cambridge: Cambridge University Press.

Horn, R.E. (1999). Visual language: global communication for the 21st century: new horizons for learning. http://www.newhorizons. org/strategies/arts/arts_review_horn.htm, visited on 2 August 2008.

Kress, G. (1997). Visual and verbal modes of representation in electronically mediated communication: the potentials of new forms of text. In Page to screen edited by I Snyder. Sydney: Allen \& Unwin.

Kress, G. (2000). A curriculum for the future. Cambridge Journal of Education 30(1), 23-36.

Lankshear, C. \& Knobel, M. (2003). New literacies changing knowledge and classroom learning. Buckingham: Open University Press.

Le Roux, C.S. (2008). Steps towards using images to develop visual literacy in environmental education contexts. Paper presented at 
the $6^{\text {th }}$ international conference on New Directions in the Humanities. Fatih University, Istanbul: Turkey. 15-18 July 2008.

Le Roux, C.S. (2009). Enhancing learning and comprehension through strengthening visual literacy. Per Linguam 25(2),46-60.

Loubser, C.P, Swanepoel, C.H \& Chako, C.P.C. (2001). Concept formulation for environmental literacy. South African Journal of Education 21(4),317-323.

Marshark, M. Pelz, J.B. Convertino, C., Sapere, P., Arndt, M.E. \& Seewagen, R. (2005). Classroom interpreting and visual information processing in mainstream education for deaf children: live or Memorex? American educational research journal. Winter 2005. Vol 42[4], 727-761.

McLaren, P. (1989). Life in schools. New York: Longman.

McMullen, P. \& Woo, L. (2002). Assessing visual literacy learning. Idt.stanford.edu/ lwoo/learning_theory.pdf, visited on 10 August 2010. Messaris, P. (1994). Visual literacy. Oxford: Westview Press.

Moore, D.M. \& Dwyer, F.M. (eds). (1994). Visual literacy: a spectrum of visual learning. New Jersey: Educational Technology Publications.

Robertson, T. (2007). Questions of seeing: images and the culture of environmental reform. American Quarterly 59(1), $239-247$.

Rose, G. (2001). Visual methodologies. London: Sage.

Shifrin, S. (2008). Visual literacy in North American secondary schools, in Visual literacy, edited by J Elkin. New York: Routledge.

Smith, M.K. (2008). Howard Gardner and multiple intelligences. The encyclopedia of informal education http://www.infed.org/thinkers Igardner.htm, visited on 13 August 2008.

Stables, A. (1998). Environmental literacy: functional, cultural, critical. Environmental Education Research 4(2), $155-164$.

Stokes, S. (2000). Visual literacy in teaching and learning: a literature perspective. Electronic Journal for the Integration of Technology in Education 1(1), 10-19.

Street, B. (1995). Social literacies: critical approaches to literacy in development, ethnography and education. London: Longman.

The New London Group. (1996). A pedagogy of multiliteracies: designing social futures. Harvard Educational Review, 66(1) http://wwwstatic.kern.org/filer/blogWrite44ManilaWebsite/paul/articles/A_Pedagogy_of_Multiliteracies_Designing_Social_Futures. htm\#11, visited on 26 August 2010.

Thibault, M. \& Wlabert, D. (S.a). Reading images: an introduction to visual literacy. http://www.learnnc.org/lp/pages/675, visited on 3 August 2008.

UNESCO. (2009). Review of contexts and structures for education for sustainable development 2009. Paris: UNESCO.

United States. National Archives and Records Administration. (s.a). Analysing photographs. http://ncmuseumofhistory.org/workshops/ civilrights1/AnalyzingPhotos_Worksheet.htm, visited on 27 July 2008.

Unsworth, L. (2001). Teaching multiliteracies across the curriculum: changing contexts of text and image in classroom practice. Buckingham: Open University Press.

Veen, G. (1998). The new visual literacy http://www.veen.com/veen/greg/seeing/main.php?sectionID=101, visited on 8 August 2008.

Walker, J.A. \& Chaplin, S. (1997). Visual culture: an introduction. Manchester: Manchester University Press.

Walsh, M.A. (2003). Multimodal learning and literacy. description of multimodal learning and literacy project http://dlibrary.acu.edu.au/ staffhome/mawalsh/research.htm, visited on 25 August 2010. 